\title{
Obituary
}

\section{In Celebration of A. Stanley Rand}

\section{W. Ronald Heyer}

Smithsonian Institution

Herpetology lost an important silverback with the death of A. Stanley Rand on 14 November 2005. Stan was born in 1932. He performed his military service from 1955 to 1957 , after which he obtained his Ph.D. under Ernest E. Williams from Harvard University in 1961. Stan and his wife Pat spent the following year in Jamaica on NSF support working on lizards of the genus Anolis. From 1962-1964 the Rands worked in Brasil (more on this below), after which Stan was hired at STRI (Smithsonian Tropical Research Institute), from which he retired as a Smithsonian Senior Scientist Emeritus in 1998.

Stan's scientific legacy extends over two domains.

The first domain consists of his more than 150 scientific publications. There are some distinct patterns to his publications. He published on all groups of amphibians and reptiles with the possible exception of tuataras (I haven't checked his lizard papers carefully). He published some initial systematic papers during and deriving from his graduate school years at Harvard, but, as time went on, it became clear that his main research interests were in the areas of behavior and ecology. The two groups of amphibians and reptiles that he performed most of his research on were lizards and frogs. From his graduate student years until 1980, the vast majority of his papers were on lizards. From 1981-1987 he published about as many papers on frogs as lizards. After 1988 through 2005, the vast majority of his papers were on frogs. In general, scholars publish most actively early in their careers, whereas Stan was noticeably more productive in publishing papers during the last

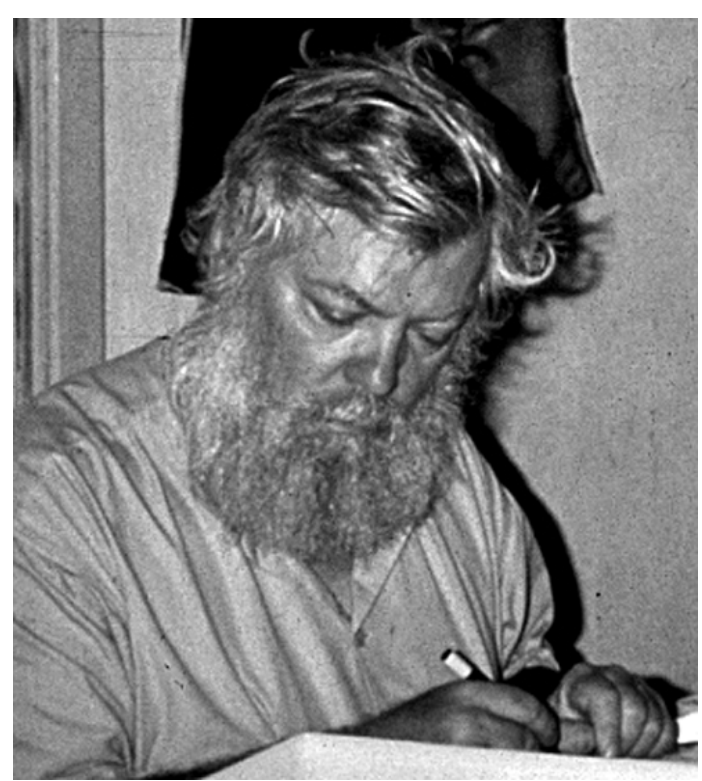

\section{A. Stanley Rand \\ $\star 1932$ ↔ 2005}

half of his career and his most productive decade was the one that ends this year. The esteem that the herpetological community had for Stan's research program is indicated by the fact that Stan was the first recipient of the prestigious Henry S. Fitch Award for Excellence in Herpetology awarded by the American Society of Ichthyologists and Herpetologists in 1998. The prize recognizes long-term excellence in the study of amphibian and/or reptile biology, based principally on the quality of the awardee's research, with consideration given to educational and service impacts of the individual's career in the field of herpetology. 
The second domain of his scientific legacy is the influence and impact he has had on many, many individuals at all stages of their careers, but particularly on students. Stan was a very social person with a quick mind and vast curiosity. He was always interested in finding out about someone's research. He asked questions of the researcher in such a way that the researcher was able to gain some new perspectives on the project and its significance. At the World Congress of Herpetology meeting this past summer, a now famous frog behaviorist asked me about Stan and told me that Stan had made a profound impact on him early in his career. Stan had approached the young frog behaviorist the day after he had given one of his first presentations at a scientific meeting. Stan told him that he found his presentation very interesting, and Stan spent some time explaining why. Then Stan inquired whether the young scholar had considered a slightly different approach to his research question. Immediately the young scholar realized that Stan's suggestion would greatly improve his research program. The young scholar appreciated that Stan had not embarrassed him by raising the point in the open discussion following his presentation and that Stan had later questioned him in a manner that encouraged rather than deflated him. Stan could also use his quick mind and provocative vocabulary to carry on heated, sarcastic, uproarious discussions, but he knew when such behavior would be invigorating or debilitating and acted appropriately to the situation. Stan touched many herpetologists in helpful and meaningful ways. It may well be that this part of his legacy is more important than his outstanding publications.

I am most familiar with Stan's work on frogs and thought I knew something about Stan based on his research and our interactions. Stan seemed to me much more enthusiastic about designing research projects, doing the research, and interpreting the results than he was in writing the results up for publication. I thought he was the consummate collaborator-catalyst: a person who wished to involve others in research which keenly interested him and a colleague who worked closely with others on the projects with a very hands-on involvement. However, if the project were to be written up in a timely fashion, the collaborators would be wise to prepare the first draft of the manuscript for Stan's extensive input. Thus, I expected to find that the vast majority of Stan's papers would be co-authored. That expectation is accurate for his frog studies. Of his 69 publications I identified as frog papers, $90 \%$ are co-authored. However, of his 55 publications I identified as lizard papers, $60 \%$ are co-authored. The differences between the frog and lizard collaborations are interesting, but inexplicable to me.

This world being the strange place that it is, Stan and I had some rather odd intersections in our careers. Paulo Vanzolini wanted to hire a visiting researcher to work out of the Museu de Zoologia in São Paulo. Vanzolini asked his good friend, Ernest Williams advice on any student that he had who would fit the bill. Williams recommended Stan to Vanzolini. Thus it was that Vanzolini hired Stan the year after obtaining his Ph.D. at Harvard. Stan was pretty much given carte blanche to do whatever research he wanted. One of the major projects Stan undertook (in collaboration with his wife Pat) was a study of the ecological organization of the frog assemblage at the museum's research station in the Atlantic Forest, Boracéia. Stan and his family made regular visits to Boracéia from December 1962 through August 1964, working on the frog fauna there. Towards the end of Stan's tenure in Brasil, Vanzolini asked Stan to write a paper on the amphibians of Boracéia. Stan recognized the value of such a work and the importance it would have to the Museum and agreed to do so. Years passed. Another herpetologist, Craig Nelson, asked Vanzolini if he and his graduate students could undertake a study on the niches of the frogs at Boracéia. Towards the end of that study, Vanzolini asked Craig if would contact Stan to pool their information and write a paper on the frogs of 
Boracéia. Craig agreed, contacted Stan, who was enthusiastic to join the effort. Years passed. Shortly after I arrived at the Smithsonian, Vanzolini paid me a visit. He asked where I was interested in collecting. I said in western Amazonia in Brasil. He invited me on such an expedition that he was planning for the following year. Thus, both Stan and I were profoundly influenced by Vanzolini early in our careers. After the first Amazon trip, Vanzolini invited me for a second expedition the following year. At the end of that second trip, my family and I spent Christmas at Boracéia in 1975. I was enthralled by the Atlantic Forest frog fauna and spent quite a bit of time at Boracéia over the next few years. Vanzolini asked me to contact Stan and write a paper on the frogs of Boracéia. I asked Stan, who was enthusiastic to do so, on the condition that Craig Nelson should be involved due to their previous agreement. Stan and I submitted a proposal and received a Scholarly Studies award from the Smithsonian Institution to fill in as many data deficiencies as possible with two more seasons of field work at Boracéia. We convinced two graduate students at the Museu de Zoologia, Carlos Alberto G. Cruz and Oswaldo L. Peixoto, to join us in the project and to concentrate on collecting and identifying the tadpoles at Boracéia. Fortuitously, Stan took a sabbatical from STRI to be in Washington DC at the time the synthetic part of the paper was ready to be written. One of the most productive and fun collaborations I have had was working on the analyses and manuscript with him. Stan and I both had vivid memories of our times with Vanzolini, whom both of us appreciated greatly. Vanzo often came up in our discussions.

The Division of Amphibians and Reptiles was fortunate to have Stan's presence after he retired from STRI the majority of each year. The curators in the Division have an informal lunch at the Divisional library table each Thursday. Stan was a regular participant in those lunch discussions whenever he was in town. He always came with a list of questions or observations to stimulate the lunch-time discussions. We miss his sparkling, mischievous eyes and the provocative and illuminating discussions in which he engaged us.

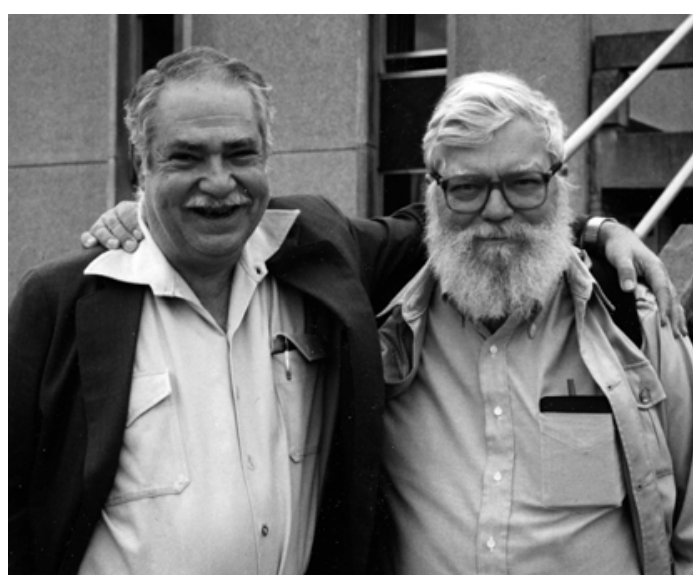

Stan Rand with Paulo Emílio Vanzolini during the First World Congress of Herpetology in England (1989). 